\title{
Impact of the SARS-COV-2 outbreak on epidemiology and management of major traumain France: a registry-based study (the COVITRAUMA study)
}

Jean-Denis Moyer ${ }^{1 *}$ (D) Arthur James², Clément Gakuba ${ }^{3}$, Mathieu Boutonnet ${ }^{4}$, Emeline Angles ${ }^{5}$, Emmanuel Rozenberg ${ }^{6}$, Jean Bardon ${ }^{7}$, Thomas Clavier ${ }^{8}$, Vincent Legros ${ }^{9}$, Marie Werner ${ }^{10}$, Quentin Mathais ${ }^{11}$, Véronique Ramonda ${ }^{12}$, Pierre Le Minh ${ }^{1}$, Yann Berthelot ${ }^{13}$, Clélia Colas ${ }^{13}$, Julien Pottecher ${ }^{14}$, Tobias Gauss ${ }^{1}$ and and the Traumabase Group

\begin{abstract}
Background: Emerging evidence suggests that the reallocation of health care resources during the COVID-19 pandemic negatively impacts health care system. This study describes the epidemiology and the outcome of major trauma patients admitted to centers in France during the first wave of the COVID-19 outbreak.

Methods: This retrospective observational study included all consecutive trauma patients aged 15 years and older admitted into 15 centers contributing to the TraumaBase ${ }^{\oplus}$ registry during the first wave of the SARS-CoV-2 pandemic in France. This COVID-19 trauma cohort was compared to historical cohorts (2017-2019).

Results: Over a 4 years-study period, 5762 patients were admitted between the first week of February and midJune. This cohort was split between patients admitted during the first 2020 pandemic wave in France (pandemic period, 1314 patients) and those admitted during the corresponding period in the three previous years (2017-2019, 4448 patients). Trauma patient demographics changed substantially during the pandemic especially during the lockdown period, with an observed reduction in both the absolute numbers and proportion exposed to road traffic accidents and subsequently admitted to traumacenters (348 annually 2017-2019 [55.4\% of trauma admissions] vs 143 [36.8\%] in $2020 p<0.005)$. The in-hospital observed mortality and predicted mortality during the pandemic period were not different compared to the non-pandemic years.

Conclusions: During this first wave of COVID-19 in France, and more specifically during lockdown there was a significant reduction of patients admitted to designated trauma centers. Despite the reallocation and reorganization of medical resources this reduction prevented the saturation of the trauma rescue chain and has allowed maintaining a high quality of care for trauma patients.
\end{abstract}

Keywords: COVID-19, Trauma, France, Traumacenter

\footnotetext{
* Correspondence: Jean-denis.moyer@aphp.fr

'Department of Anesthesiology and Critical Care, Beaujon Hospital, DMU

Parabol, AP-HP.Nord, 100 boulevard du General Leclerc, F92110 Clichy,

France

Full list of author information is available at the end of the article
}

(C) The Author(s). 2021 Open Access This article is licensed under a Creative Commons Attribution 4.0 International License, which permits use, sharing, adaptation, distribution and reproduction in any medium or format, as long as you give appropriate credit to the original author(s) and the source, provide a link to the Creative Commons licence, and indicate if changes were made. The images or other third party material in this article are included in the article's Creative Commons licence, unless indicated otherwise in a credit line to the material. If material is not included in the article's Creative Commons licence and your intended use is not permitted by statutory regulation or exceeds the permitted use, you will need to obtain permission directly from the copyright holder. To view a copy of this licence, visit http://creativecommons.org/licenses/by/4.0/ The Creative Commons Public Domain Dedication waiver (http://creativecommons.org/publicdomain/zero/1.0/) applies to the data made available in this article, unless otherwise stated in a credit line to the data. 


\section{Background}

In December 2019 Wuhan, China, experienced an outbreak of coronavirus disease 2019 (COVID-19), caused by severe acute respiratory syndrome coronavirus 2 (SARS-CoV-2) [1, 2]. This outbreak was declared a pandemic by World Health Organization, and has spread to the entire World. France was not spared and the number of COVID-19 cases has grown since the end of January 2020 and recently reached his climax in April 2020. In order to stem the spread of SARS CoV-2, the French government imposed a first national lockdown in France from March 13, 2020 for duration of 55 days.

Despite extensive public health interventions, a large number of patients were admitted to French intensive care units, mainly with acute respiratory distress syndrome (ARDS). As a consequence of the massive and constant influx of patients SARS-CoV-2 pandemic had a major impact on health care system. The COVID-19 led to a massive increase in the demand for acute care beds and challenged existing surge capacity. This required a fast and thorough restructure of the health care system [3]. The national plan for healthcare institutions (named "Plan Blanc") was deployed in order to obtain a longlasting increase of the total number of available hospital beds. A central element consisted in the postponement of non-urgent medical consultations and interventions allowing the reallocation of manpower and resources to COVID-19 patients [4].

The impact on the French trauma system was expected to be important, considering that all three key actors namely prehospital emergency services, intensive care units and anesthesiology services, were highly involved in the management of COVID-19 patients. ICU capacity usually dedicated to trauma care was reassigned to COVID-19 and other critical care admissions patients. Anesthesiologists and nursing colleagues from operating theatres were reallocated to existing or newly created critical care units. This reorganization exposed to a potential shortage of essential resources, destabilization of the trauma system and inappropriate or even deleterious delays in definitive care.

Potential mitigation was offered as a consequence of the national lockdown reducing movement and road traffic accident but in turn potentially offset by increasing numbers of assaults or fall from height secondary to suicide attempts $[5,6]$.

Altogether, these indirect effects of the COVID-19 pandemic carried the risk of detrimental effects on trauma networks with an increase of trauma related mortality. Emerging evidence suggests that the effect of the SARS-CoV-2 pandemic on overall mortality will be complex and beyond the direct consequences of the disease [7-9].
For these reasons, this study set out to explore the impact of the COVID-19 pandemic and the subsequent reorganization of the national health care system on the epidemiology, management and mortality of trauma patient admitted to trauma centers across France in the first wave of 2020. The results may identify areas of improvement for future pandemics waves and inform public health policy decisions.

\section{Methods \\ Study design}

We conducted a multicentric cohort-based observational study including data from 2017 to 2020. During each of these 4 years, all consecutive trauma admitted into 15 regional trauma centers participating in the Traumabase registry (Additional file 1) from the first week of February to the end of the second week of June were included. This study is reported according to the STROBE guidelines for observational studies [10] (Additional file 2).

\section{Data source}

The Traumabase registry prospectively collects sociodemographic, clinical, biological, therapeutic, and inhospital evolution data for all severely injured patients admitted to a participating center and suspected of severe trauma. For each patient, data collection ranges from the prehospital scene to hospital discharge. Every participating center admits all consecutive severe trauma occurring in their respective geographical area allowing for a cohort-based overview of severe trauma care in each given area. Severe trauma is defined as a situation suggesting life threatening or changing injuries (Additional file 3) [11].

\section{Data analysis}

Patients were stratified according to their year of admission, allocating those admitted the years 2017, 2018 and 2019 in one group (non-pandemic period) and those admitted in 2020 into another group (pandemic period).

To explore the effect of the lockdown, 3 periods were defined for each of these years:

- the pre-lockdown: week 6 to week 12 (respectively lasting from the beginning of the first week of February to the end of the second week of March (2017-2019) and from the February 3rd to March 16th for 2020),

- the lockdown: week 12 to week 20 (respectively lasting from the beginning of the third week of March to the end of the end of the second week of May (2017-2019) and from March 17th to May 10th for 2020), 
- and the post-lockdown: week 20 to week 24 (respectively lasting from the beginning of the third week of May to the end of the second week of June (2017-2019) and from the May 11th to June 15th for 2020).

For each year, these 3 periods were divided in 18 consecutive weeks. These consecutive weeks were matched by calendar weeks allowing for comparisons across similar segments of time across the year 2020 and previous years [eg: Weeks 16 of the previous years can be compared to Week 16 of the year 2020].

\section{Outcomes}

For each of the 3 periods, the number of patients admitted in the participating centers is reported. For each patient, age, gender, injury mechanism, injury severity (Injury Severity Score (ISS)) [12], new Simplified Acute Physiology Score (SAPS2) [13], haemorrhagic shock (transfusion of more than four blood products within 6 h) [14] and traumatic brain injury (TBI) (intracranial bleeding on CT scan), trauma management (pre-hospital and intra-hospital time, surgery during the first $24 \mathrm{~h}$, duration of mechanical ventilation length, length of stay and decision of withdrawal of care decisions) and mortality are reported. The Trauma ISS (TRISS) is used to compare the observed mortality (in-hospital mortality) to the predicted mortality [15].

\section{Statistical analysis}

Variables with an overall proportion of missing data > $10 \%$ between 2020 and previous years were not included. Missing data were not imputed and are reported for each variable in Additional file 4. All statistics were computed using Python and the Traumabase registry; no patients were excluded. Continuous variables are described by mean and standard deviation, whereas categorical variables are described in number (percentage). Each variable result over the previous years (2017, 2018 and 2019) were summarized using its mean. Significance tests were computed at a level of confidence of $95 \%$ using: a non-parametric test of Mann-Whitney for continuous variables, and a Chi- 2 test for discrete and categorical ones. The comparisons were made between 2020 and the previous years (2017-2019) on each period (pre-lockdown, lockdown and post lockdown). In order to adjust for the repeated application of statistical tests, the level of significance was set at $p<0.01$.

\section{Results}

Over the 4 year-period, 5762 patients were admitted between the first week of February and the end of the second week of June. This cohort was split between patients admitted during this time frame in 2020 (1314 patients) and those admitted during the same time frame the 3 previous years (2017-2019, 4448 patients).

Tables 1 illustrate the baseline characteristics of both cohorts.

Table 1 Epidemiology of patients admitted at Traumacenter in 2020 and compared to previous years

\begin{tabular}{|c|c|c|c|c|c|c|}
\hline \multirow[b]{3}{*}{ Variable } & \multicolumn{6}{|l|}{ Period } \\
\hline & \multicolumn{2}{|c|}{$\begin{array}{l}\text { Pre-lockdown } \\
\text { (February 3rd - March 16th) }\end{array}$} & \multicolumn{2}{|c|}{$\begin{array}{l}\text { Lockdown } \\
\text { (March 17th - May 10th) }\end{array}$} & \multicolumn{2}{|c|}{$\begin{array}{l}\text { Post-lockdown } \\
\text { (May 11th - June 15th) }\end{array}$} \\
\hline & Previous years & 2020 & Previous years & 2020 & Previous years & 2020 \\
\hline Number of admitted patients & 404 & 501 & 628 & 361 & 434 & 436 \\
\hline Age (Years) & $41.5(19.1)$ & $42.7(20.1)$ & $41.5(19.0)$ & $43.2(19.9)$ & $39.6(18.7)$ & $39.6(18.9)$ \\
\hline Gender Female) & $92(22.8)$ & $101(20.2)$ & $136(21.7)$ & $65(18)$ & $92(21.2)^{*}$ & $65(14.9)^{*}$ \\
\hline Penetrating trauma & $58(14.4)$ & $63(12.6)$ & $68(10.8)$ & $53(14.7)$ & $50(11.5)$ & $52(11.9)$ \\
\hline \multicolumn{7}{|l|}{ Mechanism of injury distribution } \\
\hline Road traffic accident & $202(50)$ & $237(47.3)$ & $348(55.4)^{*}$ & $133(36.8)^{*}$ & $245(56.5)$ & $231(53)$ \\
\hline Fall from height & $92(22.7)$ & $108(21.5)$ & $126(20.1)^{*}$ & $128(35.5)^{*}$ & $84(19.4)$ & $97(22.2)$ \\
\hline Aggression & $74(18.3)$ & $84(16.8)$ & $90(14.3)^{*}$ & $63(17.4)^{*}$ & $65(15)$ & $69(15.8)$ \\
\hline Fall from standing & $19(4.7)$ & $23(4.6)$ & $30(4.8)^{*}$ & $23(6.4)^{*}$ & $14(3.2)$ & $16(3.7)$ \\
\hline Other & $15(3.7)$ & $16(3.2)$ & $25(4)^{*}$ & $11(3)^{*}$ & $18(4.1)$ & $19(4.4)$ \\
\hline ISS & $15.6(12.6)$ & $15.0(12.5)$ & $15.8(13.4)$ & $16.4(12.6)$ & $15.0(11.9)$ & $16.2(12.3)$ \\
\hline SAPS 2 & $27.1(19.4)$ & $26.6(19.3)$ & $27.8(20.0)$ & $27.9(19.1)$ & $26.3(19.2)$ & $27.1(18.8)$ \\
\hline Hemorrhagic shock & $24(5.9)$ & $25(5)$ & $46(7.3)$ & $20(5.5)$ & $27(6.2)$ & $22(5)$ \\
\hline Traumatic brain injury & $109(27)$ & $107(21.4)$ & $152(24.2)$ & $87(24.1)$ & 105 (24.2) & $108(24.8)$ \\
\hline
\end{tabular}

* Difference between 2020 and Previous years significant with $p$ value $a \leq 0.01$ Data are N (\%), mean (Standard Deviation);

ISS Injury Severity Score, SAPS 2 Simplified Acute Physiology Score 


\section{Pre-lockdown period}

\section{Patients characteristics}

Admissions remained stable during pre-lockdown (404 admissions during the previous years vs 501 in 2020) (Fig. 1). There was no difference in patients 'characteristics and severity (Table 1).

\section{Trauma management}

Helicopter transportation (49 [12.1\%]vs $39[7.8 \%] p=$ $0.0007)$ and the rate of pre-hospital orotracheal intubation (85 [21\%]vs $82[16.4 \%] p=0.002)$ decreased without any change in total pre-hospital time $(81.9 \mathrm{~min}$ [71.4] vs $79.6 \mathrm{~min}$ [48.2] $p=0.866)$. Secondary admission from non-trauma center hospitals in previous years was equivalent to 2020 (72 [17.8\%] vs 106 [21.2\%] $p=0.035)$. The proportion of surgery performed within the first 24 h was comparable in both periods (193 [47.8\%] vs 224 [44.7\%] $p=0.029)$.

\section{Lockdown period}

\section{Patients characteristics}

The comparison highlights a significant reduction of overall admissions during the 2020 period (628 admissions during the previous years vs 361 in 2020) (Fig. 1) (Table.1). The absolute number and proportion of road traffic accidents decreased during the lockdown (348 [55.4\%] vs 143 [36.8\%] in $2020 p<0.005)$ while other mechanisms remained stable in absolute numbers (fall from height, assault, fall from standing) (Figs. 2 and 3)
(Table 1). Injury severity evaluated by ISS (15.8 [13.4] vs 16.4 [12.6] $p=0.126)$, SAPS 2 (27.9 [19.1] vs 27.8 [20.0], $p=0.415)$ and incidence of traumatic brain injury (152 [24.2\%] vs 87 [24.1\%] $p=0.704)$ and hemorrhagic shock (46 [7.3\%]vs $20[5.5 \%] p=0.350$ ) were not different from previous years.

\section{Trauma management}

Prehospital care and hospital care were similar between 2020 and previous years (Table 2). The only difference was an increase in the time in the trauma bay in 2020 (29 $\min$ [28.7] vs $33.5 \mathrm{~min}$ [46] $p=0.006$ ). The proportion of patients requiring surgical intervention in the first $24 \mathrm{~h}$ was identical (311 [49.5] vs 181 [50.1\%] $p=$ 0.418). Length of stay in the intensive care unit (ICU) (5.8 days [14.8] vs 6.8 days [13.8] $p=0.155$ ) and duration of mechanical ventilation (7.5 [11.7] days vs 9.6 [15.9] days $p=0.154$ ), were comparable to the previous years.

\section{Post lockdown period \\ Patients characteristics}

In post-lockdown, more women were affected by major trauma in 2020 (92 [21.2\%] vs 65 [14.9\%] $p=0.004)$ while the number of road traffic accidents (245 [56.5\%] vs 231 [53\%] $p=0.202$ ) was equivalent to the previous years. There was no difference in severity evaluated by ISS (15 [11.9] vs 16.2 [12.3] $p=0.04)$ and SAPS 2 scores (27.1 [18.8] vs 26.3 [19.2] $p=0.146)$ (Table 1 ).

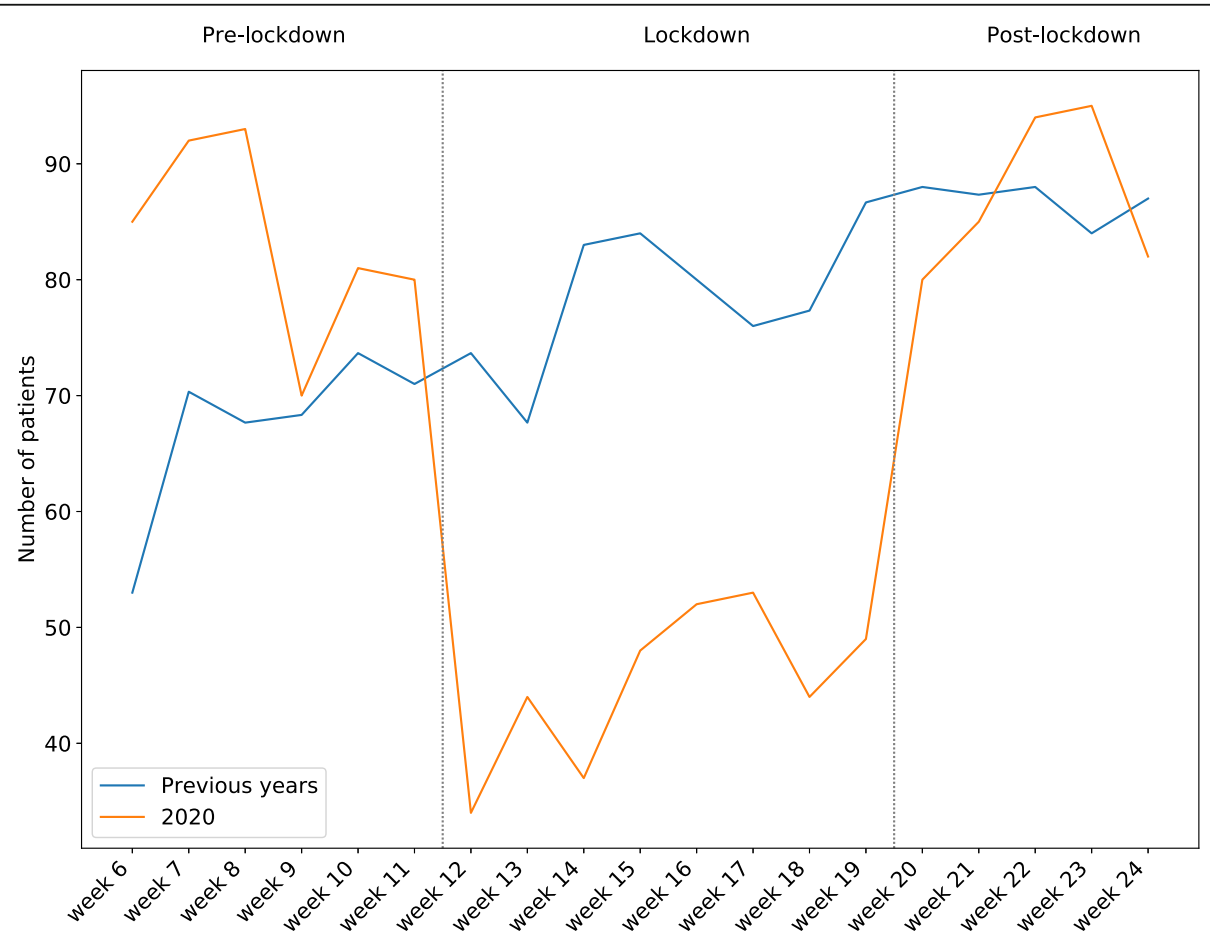

Fig. 1 Weekly number of patients admitted in Traumacenter in 2020 and compared with previous years (average of 2017-2019) 


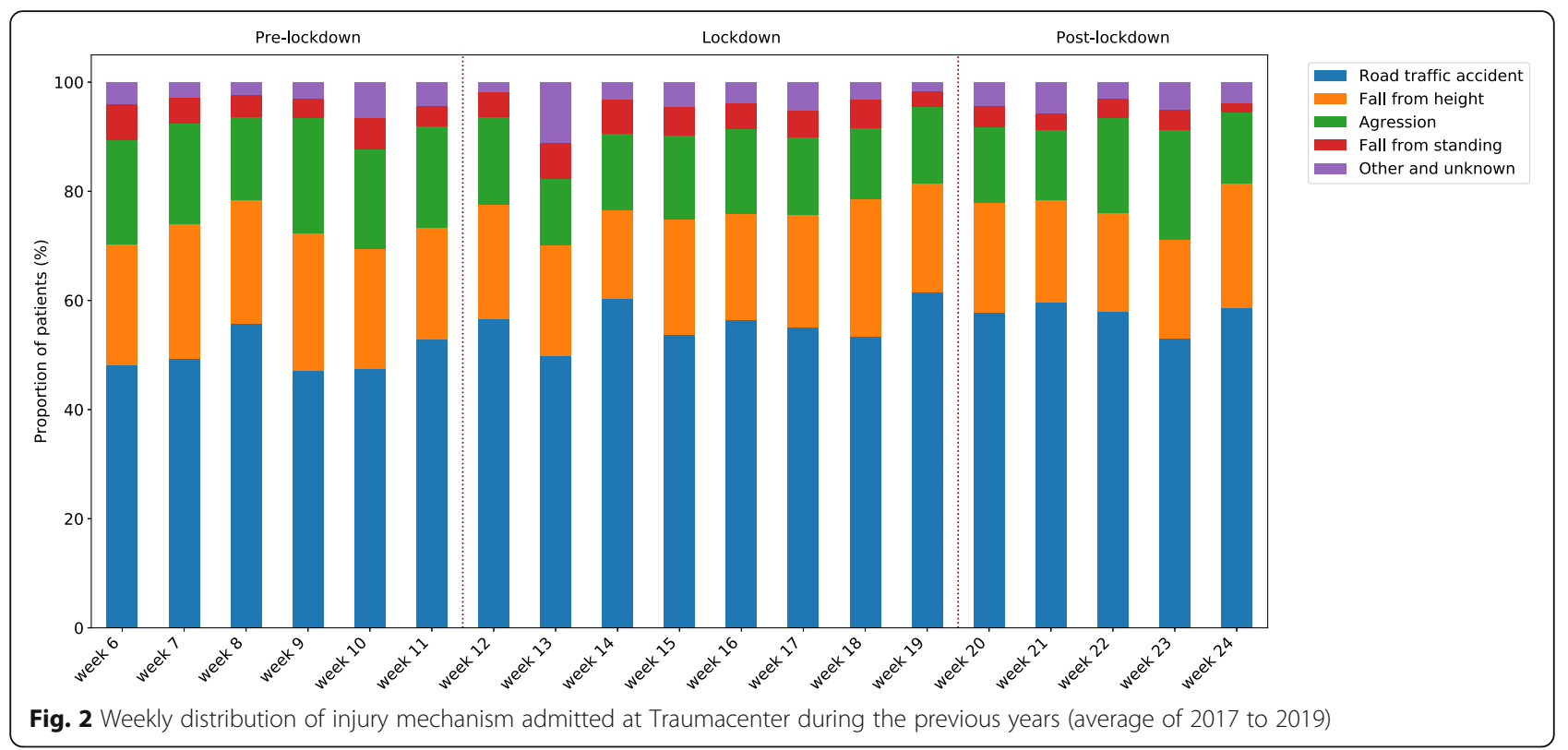

\section{Trauma management}

Prehospital care and hospital care did not differ between pandemic and non-pandemic periods (Table 2).

\section{Mortality}

The in-hospital observed mortality between previous years and 2020 remained stable throughout all three phases (Table 2) (Fig. 4). No significant difference was noted between observed and predicted mortality rates among any of the study periods (Table 2) (Fig. 4).

\section{Discussion}

\section{Overview}

To our knowledge this is the largest study on a national scale to explore the impact of the COVID-19 pandemic and the associated reallocation of health care resources on the care of major trauma patients. The results demonstrate a significant impact on the epidemiology of trauma in France during lockdown. The national lockdown reduced the overall trauma incidence in particular the frequency of road traffic accidents. The reallocation of critical care resources did not substantially alter the capacity of the health care system to provide high standards of care for the severely injured.

Several factors may explain this observation. During this COVID-192020 spring wave, a substantial volume of critical care capacity was reallocated to absorb COVID19 patients with the risk to reduce capacity available for major trauma [4]. In France, the vast majority of designated trauma centers are also the regional referral or tertiary care centers, suggesting a potential competition between patient cohorts for critical care resources. However as demonstrated by Lefrant et al. this potential effect was partially compensated by the surge in intensive

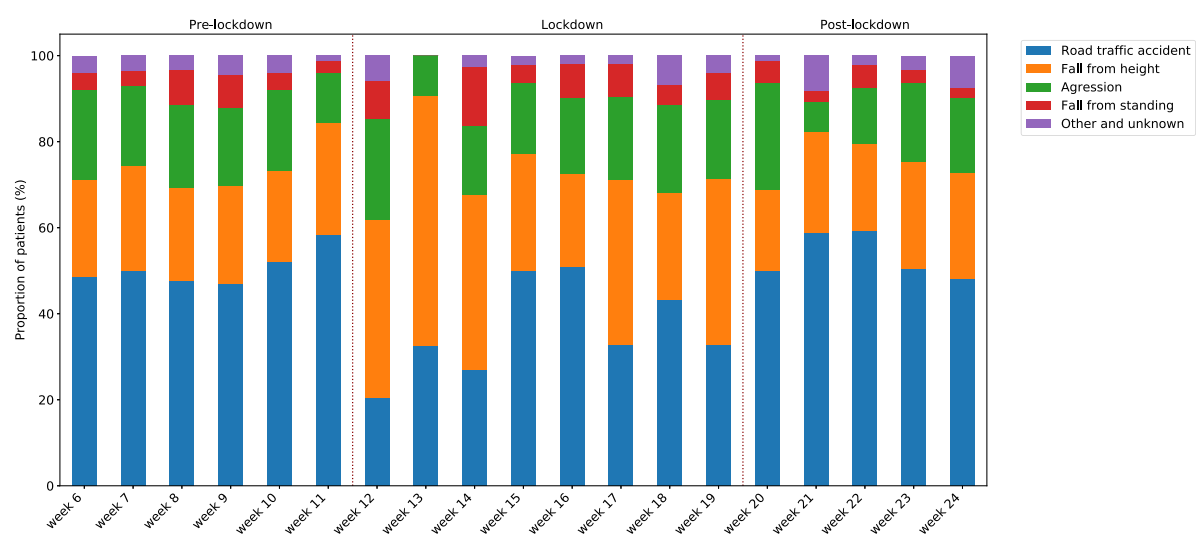

Fig. 3 Weekly distribution of injury mechanism admitted at Traumacenter in 2020 
Table 2 Prehospital and hospital management patients admitted at Traumacenter in 2020 and compared to the previous years

\begin{tabular}{|c|c|c|c|c|c|c|}
\hline \multirow[b]{3}{*}{ Variable } & \multicolumn{6}{|l|}{ Period } \\
\hline & \multicolumn{2}{|c|}{$\begin{array}{l}\text { Pre-Lockdown } \\
\text { (February 3rd - } \\
\text { March 16th) }\end{array}$} & \multicolumn{2}{|c|}{$\begin{array}{l}\text { Lockdown } \\
\text { (March 17th - May } \\
\text { 10th) }\end{array}$} & \multicolumn{2}{|c|}{$\begin{array}{l}\text { Post-Lockdown } \\
\text { (May 11th - June } \\
\text { 15th) }\end{array}$} \\
\hline & $\begin{array}{l}\text { Previous } \\
\text { years }\end{array}$ & 2020 & $\begin{array}{l}\text { Previous } \\
\text { years }\end{array}$ & 2020 & $\begin{array}{l}\text { Previous } \\
\text { years }\end{array}$ & 2020 \\
\hline Observed Mortality (in hospital) & $35(8.6)$ & $33(6.6)$ & $62(9.9)$ & $21(5.8)$ & $34(7.8)$ & $38(8.7)$ \\
\hline Predicted mortality (TRISS) (\%) & $10.8(22.7)$ & $10.3(22.1)$ & $11.0(23.1)$ & $11.7(23.6)$ & $10.4(21.6)$ & $9.4(21.2)$ \\
\hline $\begin{array}{l}\text { Variations of the difference between the predicted mortality (TRISS) and } \\
\text { observed mortality }\end{array}$ & $0.1(0.2)$ & $0.1(0.2)$ & $0.1(0.2)$ & $0.1(0.2)$ & $0.1(0.2)$ & $0.1(0.2)$ \\
\hline Transportation to hospital (helicopter) & $49(12.1)^{*}$ & $39(7.8)^{*}$ & $84(13.4)$ & $38(10.5)$ & $67(15.4)$ & $67(15.4)$ \\
\hline Pre-hospital orotracheal intubation & $85(21)^{*}$ & $82(16.4)^{*}$ & $131(20.9)$ & $70(19.4)$ & $98(22.6)$ & $87(20)$ \\
\hline Pre-hospital time (min) & $81.9(71.4)$ & $79.6(48.2)$ & $80.4(82.4)$ & $80.0(45.9)$ & $76.6(50.4)$ & $\begin{array}{l}81.2 \\
(47.8)\end{array}$ \\
\hline Intra-hospital time (min) & $28.4(26.5)$ & $\begin{array}{l}31.31 \\
(37.0)\end{array}$ & $29.0(28.7)^{*}$ & $\begin{array}{l}33.5 \\
(46.0)^{*}\end{array}$ & $27.2(26.3)$ & $\begin{array}{l}27.0 \\
(18.0)\end{array}$ \\
\hline Surgery in the first $24 \mathrm{~h}(\%)$ & $193(47.8)$ & $224(44.7)$ & $311(49.5)$ & $181(50.1)$ & $212(48.8)$ & $\begin{array}{l}217 \\
(49.8)\end{array}$ \\
\hline Immediate surgical or arteriography intervention & $14(3.5)$ & $6(1.2)$ & $21(3.3)$ & $8(2.2)$ & $15(3.5)$ & $13(3)$ \\
\hline Length of mechanical ventilation (days) & $8.8(14.3)$ & $7.5(11.2)$ & $7.5(11.7)$ & $9.6(15.9)$ & $8.2(16.3)$ & $6.5(9.1)$ \\
\hline Length of stay (days) & $6.4(13.5)$ & $5.1(8.8)$ & $5.8(14.8)$ & $6.8(13.8)$ & $6.6(20.3)$ & $5.2(8.7)$ \\
\hline Admission from non trauma center hospital & $72(17.8)$ & $106(21.2)$ & $94(15)$ & $55(15.2)$ & $65(15)$ & $76(17.4)$ \\
\hline Patient with decisions of withdrawal of care & $23(5.7)$ & $14(2.8)$ & $34(5.4)$ & $18(5)$ & $19(4.4)$ & $25(5.7)$ \\
\hline
\end{tabular}

* Difference between 2020 and Previous years significant with $p$ value $\leq 0.01$

Data are $\mathrm{N}(\%)$, mean (SD)

TRISS Trauma Related Injury Severity Score

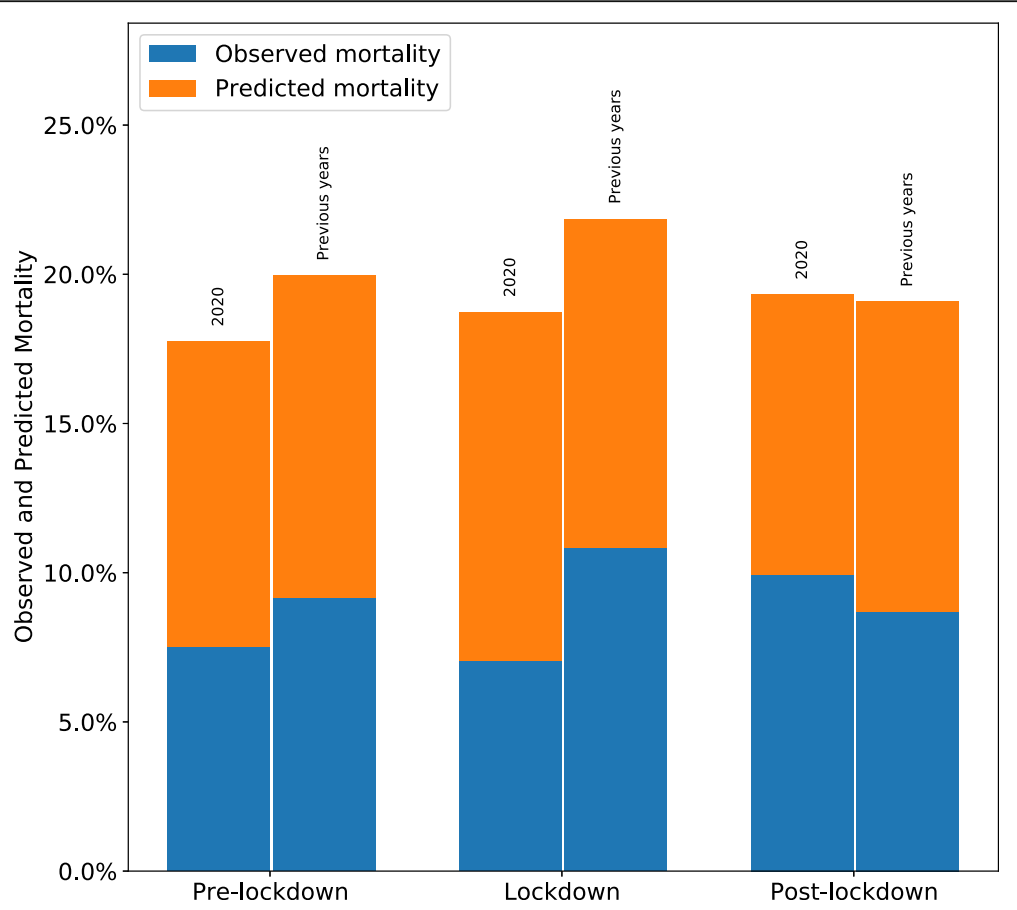

Fig. 4 Observed mortality and expected mortality during pre-lockdown, lockdown and post-lockdown in 2020 and compared to the previous years (average of 2017-2019) 
care beds [16]. Furthermore, the results document the national lockdown generated a sufficient reduction in overall trauma incidence of $43 \%$ compared to previous years. This decrease obviously prevented the overflow of trauma centers.

The injury patterns and patient characteristics in the period immediately before, during and after lockdown are very similar to the corresponding period in the previous years. The reduction in road traffic accidents was not accompanied by a surge in assault or suicide; except for road traffic accidents, all trauma mechanisms conveyed a similar number of injured victims. Trauma centers did not restrict their admission policy, as indicated by the similar median ISS across the study period, injury patterns were identical.

In terms of the quality of care, prehospital transport time did not seem different from the previous years [17]. The rate of helicopter transportation and prehospital intubations decreased slightly during the pre-lockdown period. This observation could reflect a transient adaptation during the pre-lockdown period (representing the impact of SARS-CoV-2) or a just a natural variation.

Time in the trauma bay increased slightly during lockdown, but the effect was probably minimal on patient outcome. The proportion of patients operated within the first $24 \mathrm{~h}$ remained identical suggesting timely access to complex trauma surgery was not impeded. The observed mortality and predicted mortality remained stable and comparable to previous years during this spring surge suggesting that the prehospital to intrahospital 24-h rescue chain and subsequent critical care capacity remained intact for major trauma. The trauma systems in the areas assessed in this study appeared resilient enough to absorb the shock of the 2020 COVID-19 spring surge and provide adequate and appropriate care equivalent to previous years.

These reassuring results will require re-evaluation in the case of any renewed surge of the pandemic. In fact, this first wave was characterized by a complete and imposed stop of all elective surgical and medical procedures to free up crucial resources. A new surge may not lead again to a complete cessation of interventional activity in order to provide the complete spectrum of medical care in particular for oncological cases. As stated above, the study by Lefrant et al. reported 4806 newly created ICU beds (+ 95\% increase) in France [16]. Without these adjustments, the strain on the trauma care networks could have been far higher and could have altered the level of care provided.

\section{Limitations}

The authors acknowledge some limitations inherent to the exceptional context and observational retrospective nature of the study. The results are based on data collected in fifteen trauma centers, with six centers contributing from the Paris region alone. This selection of a mix from urban and rural areas may not be representative of the entire French territory. However, the centers included are the level-1 referral centers in two of the most highly affected pandemic areas during the 2020 spring wave (Ile de France, Grand Est). The increase and intense clinical workload during the study period may have affected the capacity of clinicians and research assistants to collect data. Third, the database does not provide any data on the long-term and functional outcome of patients after TBI (such as the Glasgow Outcome Scale Extended (GOS-E) for TBI or quality of life). Consequently, we were unable to evaluate any significant outcomes other than in-hospital mortality. Moreover, the proportion of trauma patients infected with COVID-19 is unknown and the impact on their care and outcome cannot be evaluated. In addition, this study only considers patients who were admitted alive at the hospital. It is impossible to assess whether the number of severely traumatized patients who died in the pre-hospital setting has not increased [18].

\section{Conclusions}

Our study provides an insight into the epidemiology and management of trauma patients during the 2020 COVID-19 pandemic in France for the most affected areas. During this period and more specifically during lockdown, the study demonstrated a $50 \%$ reduction in road traffic accidents with no increase in alternative injury mechanisms, such as assault or suicide. The inhospital observed and predicted mortality and a number of crucial process indicators remained stable compared to previous years suggesting a sufficient resilience of the trauma networks assessed to absorb the spring 2020 pandemic hit. This study suggests that the care for major trauma patients was not substantially impacted by the SARS-CoV-2,2020 first phase in France.

\section{Abbreviations}

COVID-19: Coronavirus disease 2019; SARS-CoV-2: Severe acute respiratory syndrome coronavirus 2; ARDS: Acute respiratory distress syndrome;

ISS: Injury severity score; SAPS2: Simplified Acute Physiology Score;

TBI: Traumatic brain injury; ICU: Intensive care unit

\section{Supplementary Information}

The online version contains supplementary material available at https://doi. org/10.1186/s13049-021-00864-8.

Additional file 1: Participating centers.

Additional file 2: STROBE checklist.

Additional file 3. Vittel Criteria.

Additional file 4. Missing data proportion by variables (\%). 


\section{Acknowledgments}

The authors are indebted to all persons (data scientists, engineers, consultants, physicians) who are involved in the Traumatrix project. Special recognition goes to Ikken Mariam and Gouin Mathilde for their commitment to the coordination of the COVITRAUMA study. The authors also thank Tim Harris for his kindness to edit the manuscript.

\section{Authors' contributions}

All authors have made substantial contributions to this work and have approved the final version of the manuscript. Data collection and quality control: All Authors. Concept and design: JDM, AJ, CG, TG, JP, TC, JB. Statistical analysis: YB, CC. Interpretation of data: JDM, AJ, CG, MW, MB, TG, TC JP, CC, YB. Writing original draft: JDM, AJ, CG JP, MW, MB, TG, TC, QM, EA, $J B, V L, P L$. Writing review and editing: all authors.

\section{Funding}

None.

\section{Availability of data and materials}

The data that support the findings of this study are available from the Traumabase group but restrictions apply to the availability of these data, which were used under license for the current study, and so are not publicly available. Data are however available from the authors upon reasonable request and with permission of the Traumabase group.

\section{Declarations}

\section{Ethics approval and consent to participate}

Given the retrospective nature of the study and according to French law, the TraumaBase group obtained approval for this study, including use of data retrospectively, from the Institutional Review Board (Comité de Protection des Personnes, Paris VI, Pitié, president Pr Laurent Lacapelle, Bâtiment de la Force, 47 Boulevard de I"Hôpital, 75651 Paris Cedex 13, 28 November 2012) which is equivalent to an Ethical Committee and from the Advisory Committee for Information Processing in Health Research (Comité consultatif sur le traitement de l'information en matière de recherche dans le domaine de la santé, authorisation 11.305bis) and from the National Commission for Data Protection (Commission Nationale de l'Informatique et des Libertés, authorisation 911461).

\section{Consent for publication}

Not applicable.

\section{Competing interests}

TG reports personal fees from Laboratoire du Biomédicament Français, outside the submitted work

\footnotetext{
Author details

'Department of Anesthesiology and Critical Care, Beaujon Hospital, DMU Parabol, AP-HP.Nord, 100 boulevard du General Leclerc, F92110 Clichy, France. ${ }^{2}$ Department of Anaesthesiology and critical care, Pitié-Salpêtrière Hospital, Sorbonne University, GRC 29, AP-HP, DMU DREAM, Paris, France. ${ }^{3}$ Department of Anesthesiology and Critical Care Medicine, Caen University Hospital, Avenue de la cote de Nacre, Caen, France. ${ }^{4}$ Intensive Care Unit, Percy Military Teaching Hospital. 101 avenue Henri Barbusse 92140, Clamart, Val de Grace Academy, place Alphonse Laveran, 75005 Paris, France. ${ }^{5}$ Department of Anesthesiology and Critical Care, Bordeaux University Hospital, Pellegrin, Bordeaux, France. ${ }^{6}$ Department of Anesthesiology and Critical Care, Hôpital Européen Georges Pompidou, Paris, France. ${ }^{7}$ Department of Anesthesiology and Critical Care, Hôpital Henri Mondor, Créteil, France. ${ }^{8}$ Department of Anesthesiology and Critical Care, Rouen University Hospital, 1 rue de Germont, 76000 Rouen, France. ${ }^{9}$ Department of Anesthesiology and Critical Care, Hopital Maison Blanche - CHU de Reims, Reims, France. ${ }^{10}$ Department of Anesthesiology and Critical Care, APH-HP, Bicêtre Hôpitaux Universitaires Paris-Sud, Université Paris Saclay, Le Kremlin Bicêtre, France. " ${ }^{1}$ Department of Anesthesiology and Critical Care, Military Teaching Hospital, Sainte-Anne, Toulon, France. ${ }^{12}$ Department of Anesthesiology and Critical Care, University Toulouse 3-Paul-Sabatier, University Hospital of Toulouse, Hôpital Pierre-Paul Riquet, CHU Toulouse-Purpan, 31059 Toulouse, France. ${ }^{13}$ Capgemini Invent, Insight Driven Enterprise, focused on Data \& Artificial Intelligence services,
}

Issy-les-Moulineaux, France. ${ }^{14}$ Hôpitaux Universitaires de Strasbourg, Pôle d'Anesthésie-Réanimation \& Médecine Péri-Opératoire, Service d'Anesthésie-Réanimation \& Médecine Péri-Opératoire Hôpital de Hautepierre - Université de Strasbourg, Faculté de Médecine, Fédération de Médecine Translationnelle de Strasbourg (FMTS), UR3072, Strasbourg, France.

Received: 28 December 2020 Accepted: 5 March 2021

Published online: 22 March 2021

\section{References}

1. Huang C, Wang $Y$, Li X, Ren L, Zhao J, Hu Y, Zhang L, Fan G, Xu J, Gu X, Cheng Z, Yu T, Xia J, Wei Y, Wu W, Xie X, Yin W, Li H, Liu M, Xiao Y, Gao H, Guo L, Xie J, Wang G, Jiang R, Gao Z, Jin Q, Wang J, Cao B. Clinical features of patients infected with 2019 novel coronavirus in Wuhan, China. Lancet. 2020;395(10223):497-506. https://doi.org/10.1016/S0140-6736(20)30183-5.

2. Wang C, Horby PW, Hayden FG, Gao GF. A novel coronavirus outbreak of global health concern. Lancet. 2020;395(10223):470-3. https://doi.org/10.101 6/S0140-6736(20)30185-9.

3. Bauer J, Brüggmann D, Klingelhöfer D, Maier W, Schwettmann L, Weiss DJ, Groneberg DA. Access to intensive care in 14 European countries: a spatial analysis of intensive care need and capacity in the light of COVID-19. Intensive Care Med. 2020;46(11):2026-34. https://doi.org/10.1007/s00134-02 0-06229-6.

4. Gauss T, Pasquier P, Joannes-Boyau O, Constantin J-M, Langeron O, Bouzat $P$, Pottecher J. Preliminary pragmatic lessons from the SARS-CoV-2 pandemic in France. Anaesth Crit Care Pain Med. 2020;39(3):329-32. https:// doi.org/10.1016/j.accpm.2020.05.005.

5. Pullano G, Valdano E, Scarpa N, Rubrichi S, Colizza V. Evaluating the effect of demographic factors, socioeconomic factors, and risk aversion on mobility during the COVID-19 epidemic in France under lockdown: a populationbased study. Lancet Digit Health. 2020;S2589750020302430.

6. John A, Pirkis J, Gunnell D, Appleby L, Morrissey J. Trends in suicide during the covid-19 pandemic. BMJ (Clinical research ed.). 2020;371:m4352. https:// doi.org/10.1136/bmj.m4352.

7. Marijon E, Karam N, Jost D, Perrot D, Frattini B, Derkenne C, Sharifzadehgan A, Waldmann V, Beganton F, Narayanan K, Lafont A, Bougouin W, Jouven X. Out-of-hospital cardiac arrest during the COVID-19 pandemic in Paris, France: a population-based, observational study. Lancet Public Health. 2020; 5(8):e437-43. https://doi.org/10.1016/S2468-2667(20)30117-1.

8. Kuderer NM, Choueiri TK, Shah DP, Shyr Y, Rubinstein SM, Rivera DR, Shete S, Hsu CY, Desai A, de Lima Lopes G Jr, Grivas P, Painter CA, Peters S, Thompson MA, Bakouny Z, Batist G, Bekaii-Saab T, Bilen MA, Bouganim N, Larroya MB, Castellano D, del Prete SA, Doroshow DB, Egan PC, Elkrief A, Farmakiotis D, Flora D, Galsky MD, Glover MJ, Griffiths EA, Gulati AP, Gupta S, Hafez N, Halfdanarson TR, Hawley JE, Hsu E, Kasi A, Khaki AR, Lemmon CA, Lewis C, Logan B, Masters T, McKay RR, Mesa RA, Morgans AK, Mulcahy MF, Panagiotou OA, Peddi P, Pennell NA, Reynolds K, Rosen LR, Rosovsky R, Salazar M, Schmidt A, Shah SA, Shaya JA, Steinharter J, Stockerl-Goldstein KE, Subbiah S, Vinh DC, Wehbe FH, Weissmann LB, Wu JTY, Wulff-Burchfield E, Xie Z, Yeh A, Yu PP, Zhou AY, Zubiri L, Mishra S, Lyman GH, Rini BI, Warner $J$, Abidi M, Acoba JD, Agarwal N, Ahmad S, Ajmera A, Altman J, Angevine $\mathrm{AH}$, Azad N, Bar MH, Bardia A, Barnholtz-Sloan J, Barrow B, Bashir B, Belenkaya R, Berg S, Bernicker EH, Bestvina C, Bishnoi R, Boland G, Bonnen M, Bouchard G, Bowles DW, Busser F, Cabal A, Caimi P, Carducci T, Casulo C, Chen JL, Clement JM, Chism D, Cook E, Curran C, Daher A, Dailey M, Dahiya S, Deeken J, Demetri GD, DiLullo S, Duma N, Elias R, Faller B, Fecher LA, Feldman LE, Friese CR, Fu P, Fu J, Futreal A, Gainor J, Garcia J, Gill DM, Gillaspie EA, Giordano A, Glace (M)G, Grothey A, Gulati S, Gurley M, Halmos B, Herbst R, Hershman D, Hoskins K, Jain RK, Jabbour S, Jha A, Johnson DB, Joshi M, Kelleher K, Kharofa J, Khan H, Knoble J, Koshkin VS, Kulkarni AA, Lammers PE, Leighton JC Jr, Lewis MA, Li X, Li A, Lo KMS, Loaiza-Bonilla A, LoRusso P, Low CA, Lustberg MB, Mahadevan D, Mansoor AH, Marcum M, Markham MJ, Handy Marshall C, Mashru SH, Matar S, McNair C, McWeeney S, Mehnert JM, Menendez A, Menon H, Messmer M, Monahan R, Mushtaq S, Nagaraj G, Nagle S, Naidoo J, Nakayama JM, Narayan V, Nelson HH, Nemecek ER, Nguyen R, Nuzzo PV, Oberstein PE, Olszewski AJ, Owenby S, Pasquinelli MM, Philip J, Prabhakaran S, Puc M, Ramirez A, Rathmann J, Revankar SG, Rho YS, Rhodes TD, Rice RL, Riely GJ, Riess J, Rink C, Robilotti EV, Rosenstein L, Routy B, Rovito MA, Saif MW, Sanyal A, Schapira L, Schwartz C, Serrano O, Shah M, Shah C, Shaw G, Shergill A, Shouse G, Soares HP, Solorzano CC, Srivastava PK, Stauffer K, Stover DG, Stratton J, 
Stratton C, Subbiah V, Tamimi R, Tannir NM, Topaloglu U, van Allen E, van Loon S, Vega-Luna K, Venepalli N, Verma AK, Vikas P, Wall S, Weinstein PL, Weiss M, Wise-Draper T, Wood WA, Xu W(V), Yackzan S, Zacks R, Zhang T, Zimmer AJ, West J. Clinical impact of COVID-19 on patients with cancer (CCC19): a cohort study. Lancet. 2020;395(10241):1907-18. https://doi.org/1 0.1016/S0140-6736(20)31187-9.

9. Rosell Ortiz F, Fernández Del Valle $P$, Knox EC, Jiménez Fábrega $X$, Navalpotro Pascual JM, Mateo Rodríguez I, et al. Influence of the Covid-19 pandemic on out-of-hospital cardiac arrest. A Spanish nationwide prospective cohort study. Resuscitation. 10 oct 2020;

10. Elm E von, Altman DG, Egger M, Pocock SJ, Gøtzsche PC, Vandenbroucke JP. Strengthening the reporting of observational studies in epidemiology (STROBE) statement: guidelines for reporting observational studies. BMJ. 20 oct 2007;335(7624):806-8.

11. Hamada SR, Gauss T, Duchateau F-X, Truchot J, Harrois A, Raux M, Duranteau J, Mantz J, Paugam-Burtz C. Evaluation of the performance of French physician-staffed emergency medical service in the triage of major trauma patients. J Trauma Acute Care Surg. 2014;76(6):1476-83. https://doi. org/10.1097/TA.0000000000000239.

12. Baker SP, O'Neill B, Haddon W, Long WB. The injury severity score: a method for describing patients with multiple injuries and evaluating emergency care. J Trauma. 1974;14(3):187-96. https://doi.org/10.1097/00005373-197403 000-00001.

13. Le Gall JR. A new Simplified Acute Physiology Score (SAPS II) based on a European/North American multicenter study. JAMA J Am Med Assoc. 1993; 270(24):2957-63.

14. Roquet F, Neuschwander A, Hamada S, Favé G, Follin A, Marrache D, et al. Association of Early, High Plasma-to-Red Blood Cell Transfusion Ratio With Mortality in Adults With Severe Bleeding After Trauma. JAMA Netw Open. 2019;2(9):e1912076.

15. Boyd CR, Tolson MA, Copes WS. Evaluating trauma care: the TRISS method. Trauma Score and the Injury Severity Score J Trauma. 1987;27(4):370-8.

16. Lefrant J-Y, Fischer M-O, Potier H, Degryse C, Jaber S, Muller L, et al. A national healthcare response to intensive care bed requirements during the COVID-19 outbreak in France. Anaesth Crit Care Pain Med. 2020.

17. Gauss T, Ageron F-X, Devaud M-L, Debaty G, Travers S, Garrigue D, et al. Association of Prehospital Time to In-Hospital Trauma Mortality in a Physician-Staffed Emergency Medicine System. JAMA Surg. 2019;154(12): 1117.

18. Hamada SR, Delhaye N, Degoul S, Gauss T, Raux M, Devaud M-L, Amani J, Cook F, Hego C, Duranteau J, Rouquette A, the Traumabase Group. Direct transport vs secondary transfer to level I trauma centers in a French exclusive trauma system: impact on mortality and determinants of triage on road-traffic victims. PLoS One. 2019;14(11):e0223809. https://doi.org/10.1371/ journal.pone.0223809.

\section{Publisher's Note}

Springer Nature remains neutral with regard to jurisdictional claims in published maps and institutional affiliations.

Ready to submit your research? Choose BMC and benefit from:

- fast, convenient online submission

- thorough peer review by experienced researchers in your field

- rapid publication on acceptance

- support for research data, including large and complex data types

- gold Open Access which fosters wider collaboration and increased citations

- maximum visibility for your research: over $100 \mathrm{M}$ website views per year

At BMC, research is always in progress.

Learn more biomedcentral.com/submissions 